\title{
Comparing dynamic connective tissue in echinoderms and sponges: Morphological and mechanical aspects and environmental sensitivity
}

\author{
Michela Sugni ${ }^{a}$, Dario Fassini ${ }^{a}$, Alice Barbaglio ${ }^{a},{ }^{*}$, Anna Biressi ${ }^{a}$, Cristiano Di Benedetto ${ }^{a}$, \\ Serena Tricarico ${ }^{a}$, Francesco Bonasoro ${ }^{\mathrm{a}}$, Iain C. Wilkie ${ }^{\mathrm{b}}$, Maria Daniela Candia Carnevali ${ }^{\mathrm{a}}$ \\ a Department of Biosciences, University of Milan, Via Celoria 26, 20133 Milan, Italy \\ ${ }^{\mathrm{b}}$ Department of Life Sciences, Glasgow Caledonian University, Cowcaddens Rd, Glasgow G4 OBA, UK
}

\section{A R T I C L E I N F O}

Article history:

Received 9 July 2013

Accepted 31 July 2013

\section{Keywords:}

Echinoderms

Sponges

Collagen

Mutable collagenous tissues

Temperature

Ionic strength

\begin{abstract}
A B S T R A C T
Echinoderms and sponges share a unique feature that helps them face predators and other environmental pressures. They both possess collagenous tissues with adaptable viscoelastic properties. In terms of morphology these structures are typical connective tissues containing collagen fibrils, fibroblast- and fibroclast-like cells, as well as unusual components such as, in echinoderms, neurosecretory-like cells that receive motor innervation. The mechanisms underpinning the adaptability of these tissues are not completely understood. Biomechanical changes can lead to an abrupt increase in stiffness (increasing protection against predation) or to the detachment of body parts (in response to a predator or to adverse environmental conditions) that are regenerated. Apart from these advantages, the responsiveness of echinoderm and sponge collagenous tissues to ionic composition and temperature makes them potentially vulnerable to global environmental changes.
\end{abstract}

(c) 2013 Elsevier Ltd. All rights reserved.

\section{Introduction}

Marine invertebrates often display morphofunctional adaptations that contribute markedly to their ecological success. Echinoderms and sponges are among the most representative groups in the marine environment; despite their phylogenetic distance, they share the presence of very peculiar connective tissues, regarded as "dynamic" or "mutable", due to their unusual ability to reversibly change their mechanical properties (Wilkie, 2005; Wilkie et al., 2006). The so-called mutable collagenous tissues (MCT) of echinoderms are the best-known and characterized examples of dynamic connective tissues and their microstructure, physiology, biomechanics and biochemistry have recently undergone intensive investigation (Barbaglio et al., 2012; Ribeiro et al., 2011, 2012a, 2012b; Tamori et al., 2010; Wilkie, 2005; Yamada et al., 2010). Since in echinoderms the phenomenon of connective tissue mutability is under direct nervous control, this allows the animal to control the mechanical state of the tissue according to specific

\footnotetext{
* Corresponding author. Tel.: +390250314796.

E-mail addresses: michela.sugni@unimi.it (M. Sugni), dario.fassini@unimi.it (D. Fassini), alice.barbaglio@unimi.it (A. Barbaglio), anna.biressi@gmail.com (A. Biressi), cristiano.dibenedetto@unimi.it (C. Di Benedetto), francesco.bonasoro@ unimi.it (F. Bonasoro), i.wilkie@gcu.ac.uk (I.C. Wilkie), daniela.candia@unimi.it (M.D. Candia Carnevali).
}

functional needs (Wilkie, 2005). MCTs play a key role in echinoderm biology and ecology, being involved in many important physiological phenomena such as autotomy, asexual reproduction and energy-sparing postural control (often in cooperation with muscle activity) (Wilkie, 2005).

In sponges comparable dynamic phenomena, particularly involving changes in the mechanical properties of the collagenous mesohyl, have been reported in Pseudocorticium jarrei (BouryEsnault et al., 1995), Oscarella lobularis (Sarà and Vacelet, 1973), Chondrilla nucula (Gaino and Pronzato, 1983; Sidri et al., 2005), Plakina weinbergi (Muricy et al., 1998) and Clathrina clathrus (Gaino et al., 1991). These phenomena can be easily observed in the field, in both natural and experimental conditions, and are expressed as the marked loss of body stiffness (with production of long propagules) or by increased body stiffness after repeated mechanical stimulation. In this phylum the species demonstrating the presence of dynamic tissue most convincingly is the marine demosponge Chondrosia reniformis. This sponge shows unexpected mesohyl properties, being able to become stiff or pliant in response to specific stimuli, which is reminiscent of some mechanical aspects of echinoderm MCT. This intriguing similarity led us to investigate in depth sponge mutability in terms of microstructure (Bonasoro et al., 2001), physiology and biomechanics (Fassini et al., 2012; Parma et al., 2007; Wilkie et al., 2006). When compared with MCT behaviour, these phenomena, which are clearly cell-mediated 

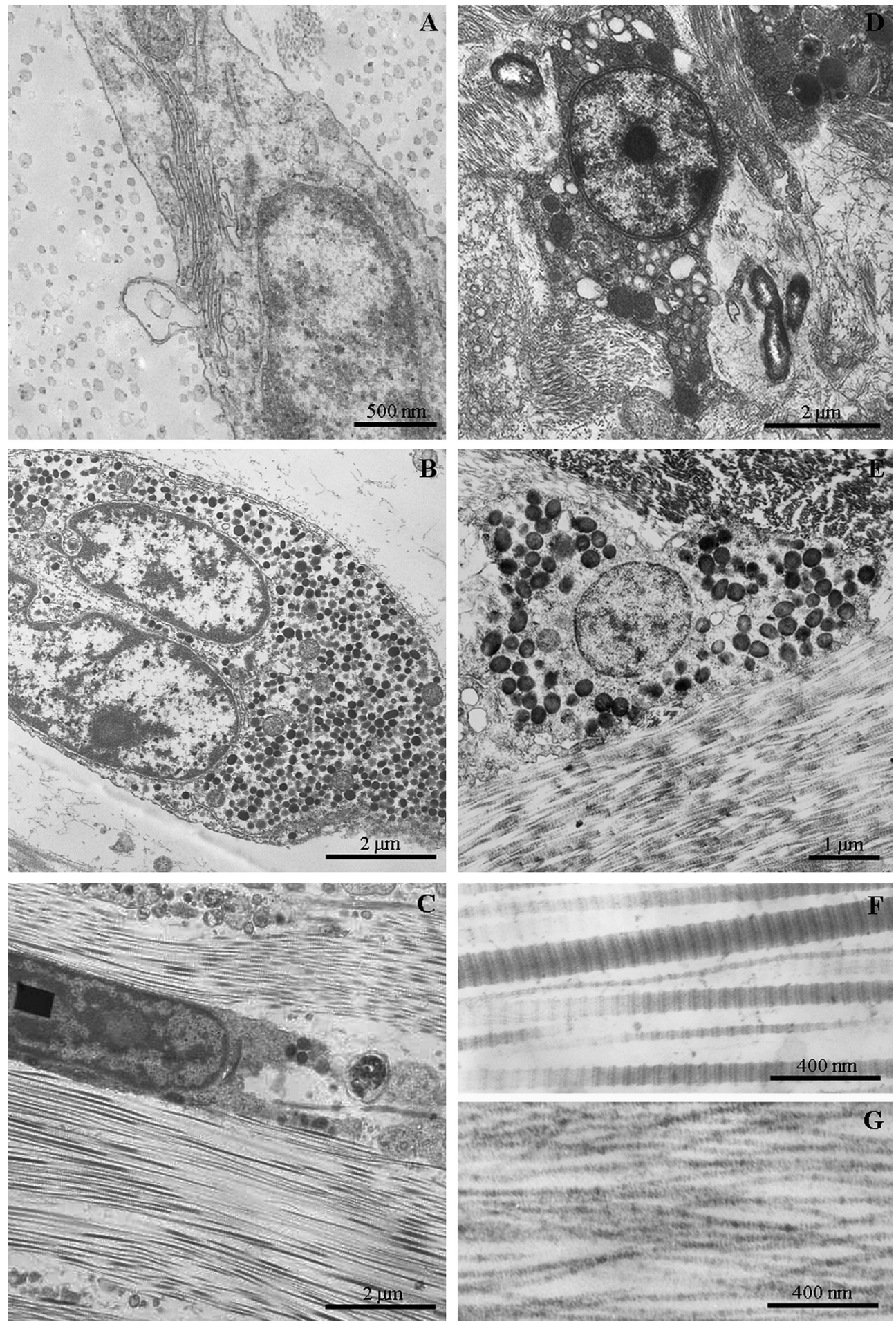

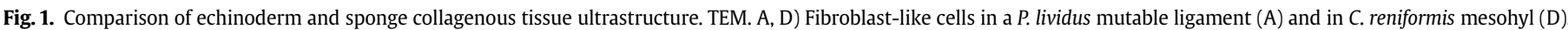

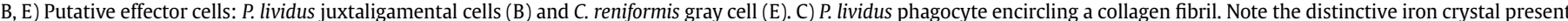
in the nucleus. F, G) Collagen fibrils: P. lividus (F) collagen fibrils show a wider diameter than those of $C$. reniformis (G).

(Wilkie et al., 2006), appear to depend closely on environmental factors (e.g. temperature and substratum instability: Fassini et al., 2012; Parma et al., 2007). In particular, the ability to lose tensility (creeping phenomenon) and produce terminal propagules when part of the substratum becomes detached is regarded as a passive form of asexual reproduction that can both preserve the viability of the parent sponge and allow the formation of a new individual by cloning (Bavestrello et al., 1998; Connes, 1967; Di Camillo et al., 2012; Fassini et al., 2012; Gaino and Pronzato, 1983; Sarà and Vacelet, 1973; Zilberberg et al., 2006). The capacity to modulate such a process could represent added value for the success of this asexual reproductive strategy, allowing the sponge to modulate the speed of creeping, or completely stop the phenomenon and the release of the terminal propagules when environmental conditions 
are not favorable (Fassini et al., 2012). On the other hand, as far as the stiffening phenomena are concerned, although their ecological significance is less clear, they could be interpreted as a defence strategy against predators.

In the following pages we provide a comparative overview of the most significant results obtained in recent years on the mutability phenomena displayed by the connective tissues of both echinoderms and sponges. We also report new data that shed light on specific morphological and biomechanical aspects, by providing further evidence on the potential influence of environmental (exogenous) factors such as temperature, $\mathrm{pH}$ and ionic composition.

\section{Morphological aspects}

\subsection{Echinoderms}

Like all connective tissues, echinoderm MCTs consist of cells and extracellular matrix (ECM), the latter dominated by collagen fibers.

\subsubsection{Cells}

Detailed morphological analysis of typical ligaments (particularly the sea urchin compass depressor ligament - CDL) has confirmed that four main cell types are present: fibroblast-like cells, phagocytes, neurons and juxtaligamental cells (the presumptive cellular effectors of mutability) (Barbaglio et al., 2012; Ribeiro et al., 2011).

In most animal models fibroblasts are the cell components characteristic of connective tissues: they are the main collagensynthesizing cells, although epithelial cells may also synthesize small amounts of collagen. Conclusive morphological descriptions of putative fibroblasts are scarce in echinoderms (Byrne, 1986; Doljanski, 2004; Smiley and Cloney, 1985). In the CDL we found several fibroblast-like cells, whose morphology varied from elongated to spherical. This high morphological variability is consistent with data from vertebrates where their appearance depends on location, matrix density and tension state (Rhee and Grinnell, 2007). Ultrastructural analyses revealed the presence of extremely long cytoplasmic processes, large amounts of intracytoplasmic multivesicular bodies, well developed Golgi apparatus and rough endoplasmic reticulum (RER), these features resembling those of mammalian fibroblasts (Mori et al., 1992; Tamariz and Grinnell, 2002) and confirming their synthetic activity (Fig. 1A). The latter was confirmed by immunodetection of prolyl 4- hydroxylase-like activity, this being a key enzyme in collagen biosynthesis (Myllyharju, 2003). These data represent the first direct evidence of collagen-synthesizing cells in echinoderms (Fig. 2B). Although uniformly distributed within the tissue, the frequency of immunoreactive cells was highly variable according to the sample (3\%-53\% of the total cells), possibly reflecting different functional states of the tissue. Whether or not an increase in their number or synthesizing activity is related to a different mechanical states has still to be elucidated.

Degradation of collagen in the CDL was observed in phagocytes, which therefore appear to have the same functional role of vertebrate fibroclasts. They were easily recognised by the presence of a typical intra-nuclear crystalloid structure (Fig. 1C; Bachmann et al., 1980) and intracytoplasmic vesicles containing collagen fibrils.

Nervous system elements were detected by both anti-tubulin and anti-synaptotagmin antibodies. Elongated cells and nerve processes were common, suggesting that the CDL is richly innervated.

Juxtaligamental cells (JLCs) were frequently detected in all MCT types: they were always easily recognizable from their large intracytoplasmic granules (Fig. 1B). The anti-synaptotagmin antibody labelled also JLCs (Fig. 2A). Since synaptotagmins are well known calcium sensors involved in the regulation of neurotransmitter release (Chapman, 2002), these results definitively confirmed the neurosecretory nature of JLCs and the possible occurrence of calcium-dependent granule exocytosis. Indeed, these data perfectly match the well-known sensitivity of MCTs to extracellular calcium variations (i.e. increasing $\left[\mathrm{Ca}^{2+}\right]$ stiffens the tissue and vice versa), which was previously only hypothesized to occur via a direct effect on the JLCs (Wilkie, 2005).

In most MCTs at least two morphologically different types of JLC are found: type $1 \mathrm{JLCs}$, containing large membrane-bounded granules, and type 2 JLCs, containing small electron-dense granules. Immunological techniques carried out on holothurian dermis indicated that type 2 JLCs store presumptive stiffening factor (tensilin), suggesting a functional distinction from the type 1 JLCs, which would possibly contain destiffening molecules (Wilkie, 2005). It was recently demonstrated that holothurian tensilin is involved only in the "compliant to standard" tensile shift (Tamori et al., 2006) whereas the stiffest state ("standard to stiff") is induced by a different molecule (novel stiffening factor-NSF: Yamada et al., 2010). Therefore it can be also speculated that the different granules contain different stiffening molecules which are released at different stages of the stiffening process. In contrast to
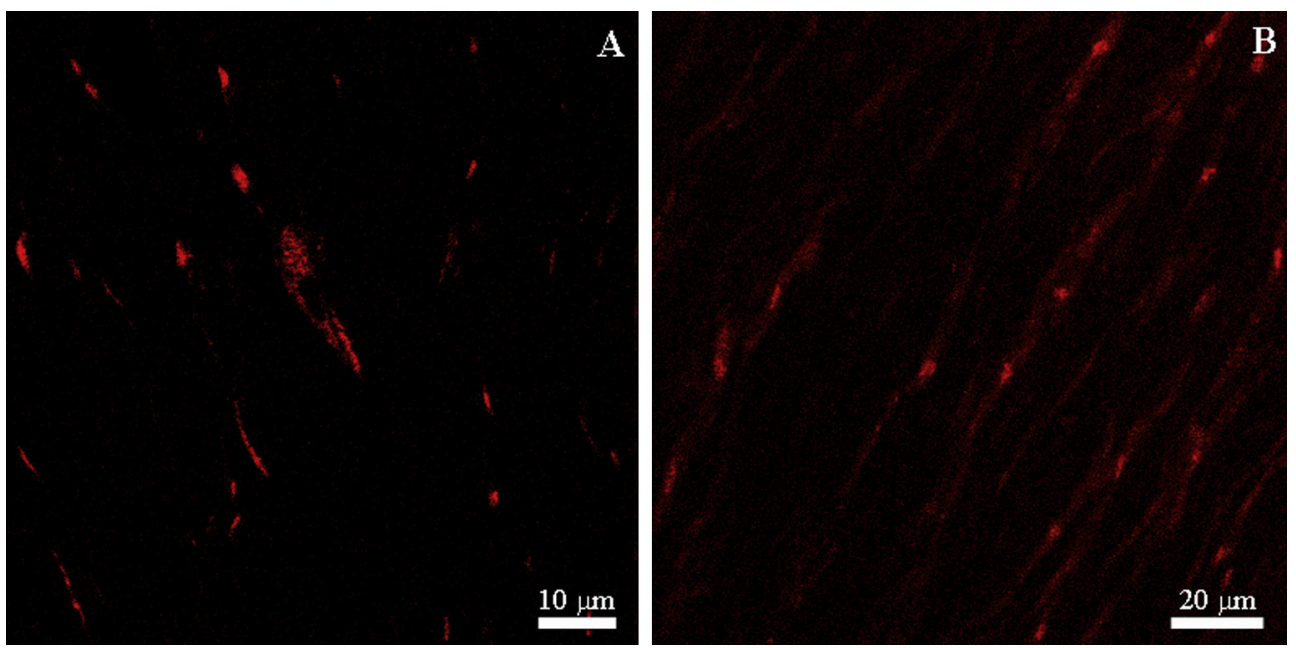

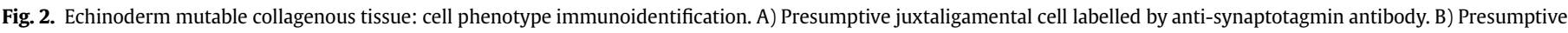
fibroblast-like cells labelled by anti-prolyl 4-hydroxylase antibody. 
most MCTs, in the sea urchin CDL we observed only one type of JLC with small electron-dense (dark) and electron-lucent (light) granules resembling those of type 2 JLCs (Ribeiro et al., 2011). In stiffened samples these cells were tightly packed between collagen fibrils and strongly aligned with them, having an elongated fusiform shape. Since no clear and unequivocal relationship between morphology (color, size and abundance) of these granules and mechanical states of the tissue could be derived, it was assumed that dark and light granules are simply different "maturation" stages, the dark one being the mature and active stage. Therefore in the CDL functionally distinct granules, if present, are not morphologically distinguishable and could therefore be found in separate as well as single cell-types (Ribeiro et al., 2011). We recently found for the first time that sea urchins also possess a tensilin-like molecule, thus strengthening an important (and possibly evolutionarily conserved) role for this molecule (Tricarico et al., 2012). Although homology in the overall amino-acid sequence is not markedly high, both the holothurian and sea urchin proteins share a TIMP-like domain, possibly indicating a similar function. Functionality tests (as described by Tamori et al., 2006) will help to clarify this aspect. Additionally, the ongoing development of specific anti-sea urchin tensilin antibody (Lima, Ribeiro, De Silva, Barbosa, unpublished) and the immunological protein localization will indicate if the sea urchin tensilin is also stored in the JLC granules, which would confirm the central role of these cells.

\subsubsection{Collagen}

Information regarding the characterization of the collagenous component of echinoderm MCT underlines the presence of interand intra-specific differences in several parameters (Exposito et al., 2010). The first biochemical analyses from Matsumura et al. (1979) evidenced similarities between starfish and sea cucumber collagens and between sea urchin and brittle star collagen, leaving crinoids is a separate category. Up to seven collagen sequences were identified in sea urchins (Aouacheria et al., 2004; Cluzel et al., 2004; D'Alessio et al., 1990; Exposito et al., 1995; Saitta et al., 1989). Sea urchin embryos showed immunoreactivity against antibodies to vertebrate type I, III and IV collagens (Wessel et al., 1984). Labeling of adult tissues was performed in our lab (Barbaglio et al., in preparation). The collagen fibril D period ranges from $44 \mathrm{~nm}$ (Strongylocentrotus purpuratus peristomial membrane: Burke et al., 1989) to $67 \mathrm{~nm}$ (holothurian dermis: Matsumura, 1974) (Fig. 1F). Molecular data revealed similarities between sea urchin and vertebrate collagen type I (Cluzel et al., 2000; D'Alessio et al., 1990; Ribeiro et al., $2012 b)$ in terms of chain composition $\left(2 \alpha_{1}+1 \alpha_{2}\right)$, gene organization and spectroscopy profiles, although the similarities are not striking. Our on going bioinformatic and biochemical analyses confirm these findings (Barbaglio et al., in preparation). Unlike sea urchins, holothurians show a $3 \alpha_{1}$ arrangement (Trotter et al., 1995). A unique characteristic of sea urchin collagen is the presence of a specific $N$-propeptide domain of the $\alpha_{2}$ chain (SURF domain: Exposito et al., 1992) identified in $S$. purpuratus and absent from other echinoderm and vertebrate models. Sea urchin and sea cucumber collagens also need different extraction procedures, the former requiring reducing agents ( $\beta$-mercaptoethanol) to be extracted (Trotter and Koob, 1989) and thus possibly indicating different types of interfibrillar bonds. Nevertheless the mutability phenomenon is widely evident in both classes, thus indicating that the specific collagen molecular and ultrastructural organization does not influence the viscoelastic changes (a suggestion that is spectacularly endorsed by the mutability of ophiuroid tendons, which are likely to consist mainly of non-fibrillar type IV collagen: Wilkie and Emson, 1987). Furthermore, fibril integrity is maintained during these changes (Ribeiro et al., 2011). Interfibrillar sliding coupled with breakage/reformation of interfibrillar links are hypothesized to be responsible for the biomechanical variations (Barbaglio et al., 2012; Wilkie, 2005). Acid and pepsin extracted fibril fragments showed good fibrillogenesis in vitro at about $20^{\circ} \mathrm{C}$, whereas incomplete or aberrant self-assembling was registered at $37{ }^{\circ} \mathrm{C}$, thus suggesting that the thermal stability of echinoderm collagen differs from that of mammalian collagen (Trotter and Koob, 1994). Collagen denaturation temperature is $28^{\circ} \mathrm{C}$ in Anthocidaris crassispina (Nagai and Suzuki, 2000) and $18{ }^{\circ} \mathrm{C}$ in Parastichopus californicus (Liu et al., 2010). Robinson (1997) showed that S. purpuratus collagen is more sensitive to collagenase and to heat denaturation than rat tail collagen.

\subsection{Sponges}

\subsubsection{Cells}

The cellular components of the sponge mesohyl (which consists of an outer 'ectosome' and inner 'choanosome') are mainly lophocytes and spherulous cells. In C. reniformis lophocytes appeared as fibroblast-like cells scattered throughout the mesohyl, whereas spherulous cells were mainly present in the cortical layer, in the ectosome-choanosome transition region and in the areas surrounding the canals (Bonasoro et al., 2001). Spherulous cells were characterized by the presence of large membrane-bounded inclusions (spherules) and were thought to be involved in the modulation of the mechanical properties of the sponge (Bonasoro et al., 2001; Wilkie et al., 2006). A third less frequent cytotype was represented by gray cells (Fig. 1E). In C. reniformis these cells displayed some similarities to echinoderm JLCs, their characteristic feature being the presence of small and electron-dense paracrystalline granules: for this reason it was suggested that they play a role in the regulation of mesohyl mutability. The last phenotype was represented by actinocytes, whose cytoplasm was characterized by the prominent occurrence of actin filaments. Actinocytes were found scattered around the canals, particularly in the region surrounding the osculum where they tended to follow an orthogonal arrangement (Pavans de Ceccatty et al., 1970). The previous hypothesis that these cells control sponge mechanical properties, is not currently supported, their total number and mass being too small to explain the magnitude of $C$. reniformis mechanical changes (Wilkie et al., 2006).

Correlations between ultrastructural and mechanical changes were observed in the spherule contents of spherulocytes and in the actin filament organization of actinocytes (Bonasoro et al., 2001). In the stiffened condition the actinocytes displayed a more evident cytoskeletal apparatus than in the standard condition. In addition, in the stiffened condition, cells and collagen fibrils looked more tightly packed. No evident changes were observed in the spherulocytes of stiffened sponges; in contrast, during the creeping phenomenon, in the sponge elongation region the spherulocytes appeared to be more irregularly distributed and their contents more heterogeneous. Despite their apparent similarity to echinoderm JLC type 2, gray cells did not display any evident difference in the different mechanical states (Bonasoro et al., 2001), their specific content and functional role being still undetermined. Further analyses are therefore needed to definitively establish the cell phenotype(s) directly involved in sponge mutability.

\subsubsection{Collagen}

The mesohyl of the sponge $C$. reniformis is composed mainly of a dense meshwork of bundles of collagen fibrils. Most of the fibrillar collagen resembles vertebrate collagen type I, although differences in the solubilisation in acid solutions suggest that bonds between microfibrils are stronger in the sponge (Heinemann et al., 2007). Quantitative analysis reported a mean fibril diameter of $20 \mathrm{~nm}$, a length of several hundred microns, and an aspect ratio more than 

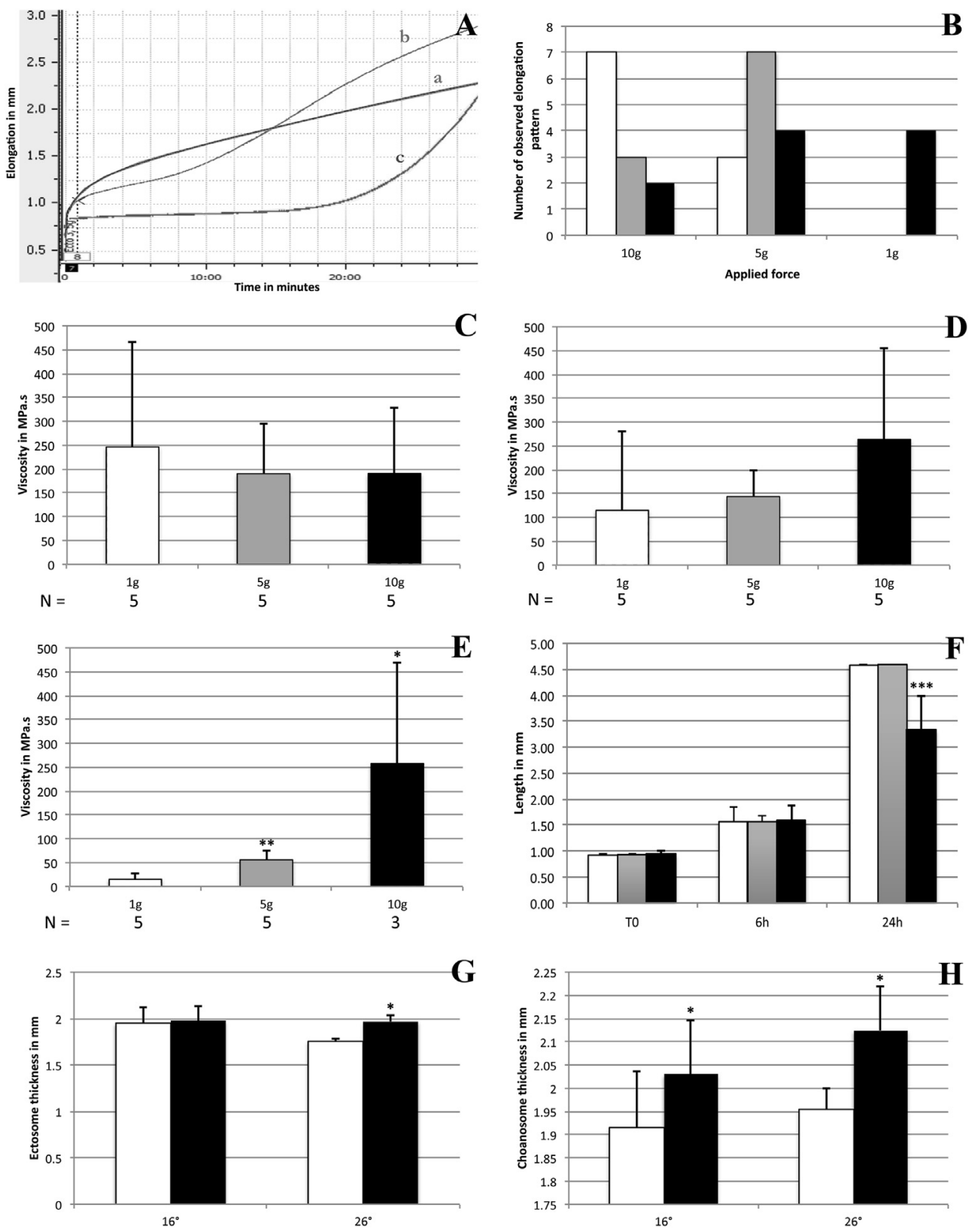

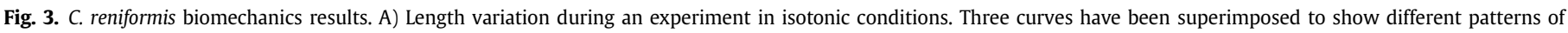

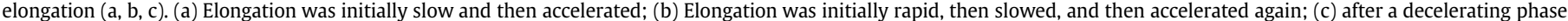

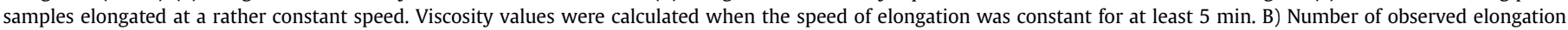

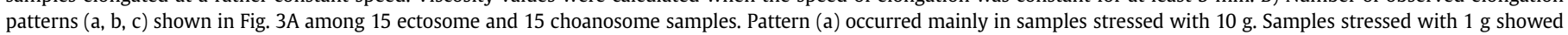

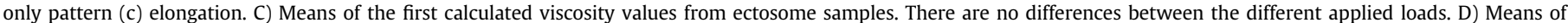

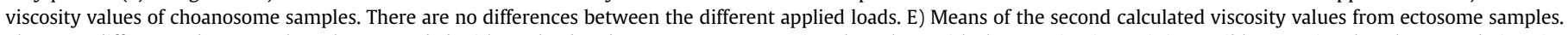

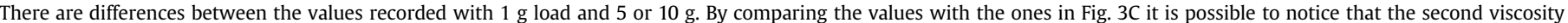

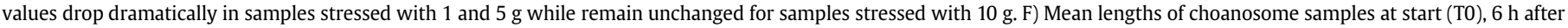

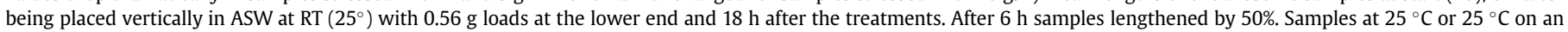

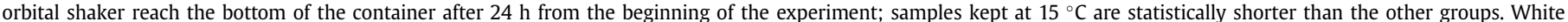

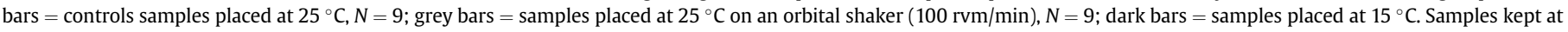

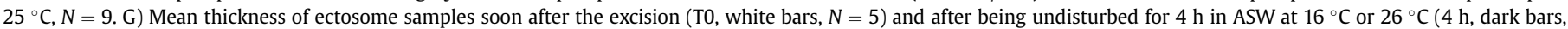

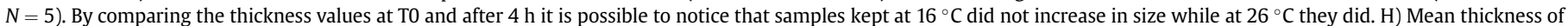

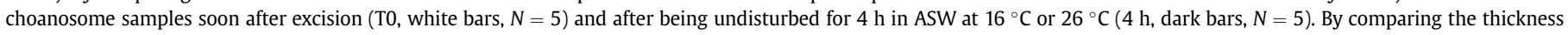

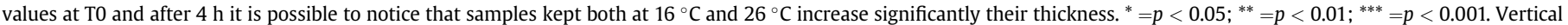
bars $=$ standard deviations.

1:5000, similar to those of echinoderms (Heinemann et al., 2007). In the TEM (Fig. 1G), the presence of two separate electron-lucent bands plus one electron-dense band of $22 \mathrm{~nm}$ each characterized the fibril banding period of $C$. reniformis, the average $D$ band period being $66 \mathrm{~nm}$ (Bonasoro et al., 2001).
In addition, the presence of non-fibrillar type IV-like collagen (COLch), belonging to the short-chain spongin-like collagen family, was recently described (Pozzolini et al., 2012). This collagen was much more abundant in the sponge cortical layer and, due to the presence of specific protein-protein interaction domains (Pozzolini 
et al., 2012), could play a role in the modulation of the mechanical properties by interacting with the fibrillar component.

No ultrastructural modifications of collagen fibrils were demonstrated in relation to the different dynamic phenomena of the mesohyl. Nevertheless, in the stiff state the fibril arrangement looked much more compact and than in standard condition, whereas, during the creeping phenomenon, collagen bundles in the elongation region appeared to be arranged more loosely and often reciprocally disaggregated (Bonasoro et al., 2001).

\section{Biomechanical aspects}

\subsection{Echinoderms}

Biomechanical aspects of echinoderm MCT have been explored intensively. It has been firmly established that dramatic changes in MCT passive mechanical properties can occur in vivo and be experimentally induced by specific treatments (Ribeiro et al., 2012a, 2012b; Tamori et al., 2006; Wilkie, 2005; Yamada et al., 2010). In particular, neurotransmitters and other neuro-active drugs have been demonstrated to exert marked effects on the MCT mechanical state, confirming that mutability is under nervous control. Acetylcholine is the main neural-derived stiffening agent on MCTs, being effective on most of the studied MCT models (Hidaka and Takahashi, 1983; Ribeiro et al., 2011, 2012a, 2012b; Wilkie et al., 1994, 1992). The cholinergic control of MCT has been further demonstrated by the observed increase in stiffness and/or viscosity following treatment with cholinergic agonists (Birenheide et al., 1998; Wilkie et al., unpublished). However, the specific neural circuit involved in MCT destiffening is still unclear, mainly due to contrasting results obtained so far: whereas adrenaline reduced tensile strength and elastic modulus of the sea urchin spine ligament (Hidaka and Takahashi, 1983), it was apparently ineffective on the CDL of Paracentrotus lividus (Wilkie et al., unpublished); similarly, in the crinoid arm L-glutamate induced autotomy (Wilkie et al., 2010), and therefore irreversible MCT destiffening, whereas L-glutamate (as well as other noncholinergic agonists) had no mechanical effect on the sea urchin CDL (Wilkie et al., unpublished). For this reason, in our experiments we usually induced the compliant state by treatment with the anaesthetic propylene phenoxetol (Ribeiro et al., 2011, 2012a, 2012b; Wilkie et al., 1992). Apart from neuro-active agents, other compounds or agents can exert direct or indirect effects on MCT biomechanics. Several experiments showed that treatments causing cell membrane lysis (such as distilled water, detergents, freeze-thawing) could induce a marked increase in MCT stiffness (Wilkie, 2005), indicating that the stiffening factor(s) are normally contained in cells and may be released into the ECM after membrane disruption. Finally, very recent studies (Ribeiro et al., 2012a) demonstrated that the MCT stiffness and storage modulus can be reversibly increased by a compound (galardin) that inhibits matrix metalloproteases (MMPs), which are well known ECM remodellers in vertebrates and have an important role in mammal uterine cervix relaxation at parturition (another example of connective tissue dynamicity).

\subsection{Sponges}

Demosponges display remarkable differences in mesohyl mechanical properties between stiffened and standard conditions (Wilkie et al., 2006; Fassini et al., in preparation). As for echinoderm MCTs, treatments influencing cellular activity, including inorganic and organic calcium channel-blockers and cell membrane disrupters, induced sponge stiffening (Wilkie et al., 2006). Furthermore, it was also demonstrated that treatment with tissue extracts provoked mesohyl reactions comparable to those of typical MCTs, which led us to hypothesize that stimulation releases into the ECM a stiffening factor, stored in cells in the resting condition, which modifies interactions between collagen fibrils (Wilkie et al., 2006). Preliminary experiments carried out on isolated ectosome and choanosome samples showed that elongation could be induced under a constant load and revealed unusual responses of the sponge when subjected to different mechanical stresses. In particular, both ectosome and choanosome samples underwent elongation when subjected to a constant load: a first phase of deceleration of the elongation speed was followed by a period of rather constant elongation speed from which the viscosity was calculated (Fig. 3A). It was often observed that, after 5-20 min, there was a dramatic increase in the elongation speed (indicating a decrease in viscosity) (Fig. 3A: curves a and b), these changes being presumably related to the different magnitude of the applied stress (Fig. 3B). The initial viscosity values were respectively $208 \pm 151 \mathrm{MPa}$ s (range 5$586 \mathrm{MPa}$ s) for the ectosome, and $174 \pm 153 \mathrm{MPa}$ s (range 3.5$554 \mathrm{MPa}$ s) for the choanosome. The first viscosity values did not appear to be related to the applied stress for either the ectosome (Fig. 3C) or the choanosome (Fig. 3D). Since several ectosome samples showed changes in the elongation speed, we could calculate the mean viscosity values of the second constant phase. Here we found that only the values obtained with a load of $10 \mathrm{~g}$ were comparable to those of the first viscosity phase, whereas samples loaded with $1 \mathrm{~g}$ and $5 \mathrm{~g}$ showed lower viscosity (Fig. 3E). These findings suggest that, after an initial phase, which is independent of the applied stress, in the second phase the viscosity was proportional to the applied load. This behaviour could be explained by the fact that the passage from stiffened to standard condition could be delayed when the applied stress exceeds a specific threshold value. The subsequent ectosome values obtained after $5-20 \mathrm{~min}$ from the application of the load were $14.7 \pm 11.4 \mathrm{MPa} s$ for a nominal stress of $0.0168 \mathrm{MPa}$; $55.9 \pm 19.87 \mathrm{MPa} s$ for a nominal stress of $0.0839 \mathrm{MPa}$ and $257.54 \pm 212.85 \mathrm{MPa}$ s for a nominal stress of $0.1677 \mathrm{MPa}$ (Fig. 3E).

In addition, preliminary tests carried out in our laboratory indicated that mechanical changes in sponges could also be sensitive to neuro-active agents, such as L-glutamate (Fassini et al., unpublished).

\section{Effects of environmental factors on mutability}

\subsection{Echinoderms}

\subsubsection{Temperature}

The effects of temperature variation on MCT properties have not been investigated in depth. Hidaka (1983) examined the influence of temperature on the tensility sea urchin spine ligaments. The tensile strength and apparent stiffness were significantly reduced by a $10^{\circ} \mathrm{C}$ decrease in temperature (from $20^{\circ} \mathrm{C}$ to $10^{\circ} \mathrm{C}$ ), whereas no significant changes were registered with a $10{ }^{\circ} \mathrm{C}$ increase in temperature (from $20{ }^{\circ} \mathrm{C}$ to $30^{\circ} \mathrm{C}$ ). The author surmised that the decrease in biomechanical values could be a consequence of a lower probability of linkage reformation, or could indicate the intervention of temperature-dependent hydrophobic interactions (Nemethy, 1988) in the mutability mechanism. Pincebourde et al. (2013) recently showed that in starfish, during aerial exposure at low tide, the incidence of arm autotomy increased when body temperature reached $33{ }^{\circ} \mathrm{C}$. Arm loss was consistently more frequent in the hottest examined individuals, thus suggesting that in intertidal echinoderms autotomy (involving irreversible MCT destiffening) could also have an ecological role in avoiding overwarming of the total body, especially of the central disk where vital organs are located. The significance of the effect of temperature on reversible MCT destiffening (as in e.g. sea urchin spine and 
compass depressor ligaments and holothurian dermis) still needs to be clarified.

\subsection{2. $\mathrm{pH}$}

The pattern of response of MCTs to changing $\mathrm{pH}$ varies between tissues. The viscosity of the ophiuroid intervertebral ligament increased at $\mathrm{pH}$ values below 8, decreased at $\mathrm{pH}$ 9-11 and increased again above $\mathrm{pH} 11$ (Wilkie, 1988). An increase to $\mathrm{pH} 9$, or higher, caused an increase in viscosity of both sea urchin spine ligaments (Hidaka, 1983) and holothurian introvert (Byrne, 1985). A decrease in $\mathrm{pH}$ below physiological levels determined a decrease in viscosity in sea urchins and an increase in holothurians (Byrne, 1985). Changes in pH probably influence MCT mechanical properties by changing the number and distribution of charged groups on ECM macromolecules and, consequently, tissue electrostatic and steric interactions (Hidaka, 1983). However, large pH changes in vivo are unlikely, so that they could hardly be considered a physiological mechanism acting during mutability. It is speculated that ocean acidification will cause a decrease of $0.3-0.4 \mathrm{pH}$ unit by 2100 (Makarow et al., 2009). Although such a small change is unlikely to affect MCT mechanisms in physiological timescales, possible long-term effects have still to be investigated.

\subsubsection{Ionic environment}

The viscous resistance of MCTs is strongly dependent on the ionic composition of the medium, particularly to $\mathrm{K}^{+}, \mathrm{Ca}^{2+}$ and $\mathrm{Mg}^{2+}$ concentrations. High $\left[\mathrm{K}^{+}\right]$induced an increase in stiffness in several reversible MCTs, e.g. P. lividus CDL (Wilkie et al., 1992), A. crassispina spine ligament (Hidaka and Takahashi, 1983) and Asterias rubens tube feet (Hennebert et al., 2010), whereas decreased viscosity in irreversible MCTs, e.g. crinoid cirral ligament (Wilkie, 1983), holothurian introvert (Byrne, 1985) and ophiuroid intervertebral ligament (Wilkie, 1988). These contradictory effects suggest that the response to $\mathrm{K}^{+}$is tissue-specific. Furthermore, $\mathrm{K}^{+}$is considered not to act directly on the collagenous ECM but via depolarization of neurons controlling effector cells (Wilkie et al., 1994). Increased $\left[\mathrm{Ca}^{2+}\right]$ caused increased stiffness in numerous models (holothurian dermis, sea urchin spine ligaments, starfish tube feet: Hennebert et al., 2010; Szulgit and Shadwick, 1994; Trotter and Koob, 1995). Excess $\mathrm{Mg}^{2+}$ had the same effect on holothurian introvert (Byrne, 1985), whereas it lowered the viscous resistance of echinoid spine ligaments (Hidaka, 1983). As in the case of $\mathrm{K}^{+}$, the effects of $\mathrm{Ca}^{2+}$ and $\mathrm{Mg}^{2+}$ may be neurally mediated. Contrary to previous hypotheses that regarded $\mathrm{Ca}^{2+}$ as having a direct role in the modulation of ECM cohesion (Wilkie, 1996), it has been shown that specific treatments stiffen significantly MCT even in the absence of $\mathrm{Ca}^{2+}$ ions (see e.g. Szulgit and Shadwick, 1994). New results related to synaptotagmin immunodetection support the view that $\mathrm{Ca}^{2+}$ is involved at the level of cellular processes controlling MCT tensility (see 2.1.1 above).

\subsection{Sponges}

\subsubsection{Temperature}

The so-called creeping phenomenon was demonstrated to be seasonal and related to sea water temperature (Fassini et al., 2012; Parma et al., 2007). The hypothesis that wave action could also play a role by slowing down the phenomenon can now be rejected on the basis of our experiments on isolated choanosome samples. Here we showed that decreased sea water temperature is the only factor that affects the speed of the phenomenon (Fig. 3F). Sea water temperature appears to play an important role for the asexual reproduction strategies of this sponge, representing a useful feedback mechanism that could decelerate or prevent the release of the propagules during unfavourable seasons. This suggests the possibility that abnormally high sea temperatures could trigger the phenomenon during unfavourable periods leading to the failure of the asexual reproduction.

Other effects of temperature are related to the recovery process that follows after the sponge stiffens as a result of mechanical manipulation. Cutting the sponge resulted in both stiffening and appreciable reduction in the size of tissue samples (Wilkie et al., 2006; Fassini, unpublished). Cut samples, if left undisturbed, within few hours became softer (Wilkie et al., 2006), the ectosome appearing to be much more influenced by temperature than the choanosome. The dimensional gain that occurred during this softening period showed again that the ectosome is much more sensitive to changes in temperature (Fig. 3G) than the choanosome (Fig. $3 \mathrm{H}$ ), thus suggesting that the ectosome could be much more involved in, and responsible for, the regulation of the dynamic phenomena that occur in the sponge.

All these data demonstrate that temperature plays an important role in the control of different aspects of the biology of $C$. reniformis. Although there are no published data on the effect of a long-term change in sea temperature, it is possible that an increase in the sea temperature during winter/early spring could disturb the feedback mechanism that prevents the release of propagules when ecological factors are still adverse to the survival of propagules.

\subsubsection{Ionic environment}

Data on the effects of ionic manipulation on the mechanical properties of $C$. reniformis concern mostly changes in the extracellular and intracellular $\left[\mathrm{Ca}^{2+}\right]$. The role of $\left[\mathrm{Ca}^{2+}\right]$ is still controversial since its manipulation could disturb different processes (Wilkie et al., 2006). The results obtained so far showed that both organic and inorganic $\mathrm{Ca}^{2+}$ channel blockers and the intracellular $\mathrm{Ca}^{2+}$ chelator EGTA-AM inhibit the destiffening of maximally stiffened samples, and stiffen partially destiffened samples, suggesting that both these processes are influenced by cellular processes involving transmembrane $\mathrm{Ca}^{2+}$ fluxes and changes of intracellular $\left[\mathrm{Ca}^{2+}\right]$. On the extracellular side, increasing $\left[\mathrm{Ca}^{2+}\right]$ retarded the destiffening process of maximally stiffened samples, whereas samples kept in CaMgFSW showed accelerated destiffening. Surprisingly, keeping samples in CaMgFSW with $1 \mathrm{mM}$ EGTA strongly inhibited destiffening, and CaMgFSW with 2 mM EGTA restiffened partially destiffened samples. Whilst $\left[\mathrm{Ca}^{2+}\right]$ variations appear to act on the physiology of cells (Wilkie et al., 2006), it is still possible that calcium could also contribute directly to the stabilization of the ECM.

At present, there is no information on the effects of $\mathrm{pH}$ variation on the mechanical state of sponges.

\section{Comparative aspects and conclusions}

We have provided an over-view of some essential and crucial aspects of connective tissue mutability in echinoderms and sponges. Despite the overall similarities in the behaviour of their connective tissues, and the obvious analogies in terms of morphology, physiology and biomechanics, there are significant differences in some crucial aspects which deserve detailed discussion. In both phyla the histology and ultrastructure is typical of fibrous connective tissue, which means that the characteristic component is an array of collagen fibrils in which different cell phenotypes are scattered. Nevertheless, an initial difference is presented by the collagen fibrils themselves. Sponge fibrils are rarely organized into bundles (fibers) and their mean diameter is much lower than that of echinoderm fibrils (Fig. 1F and G). Since larger fibrillar bundles are usually formed as a result of crosslinking with different molecules (such as glycoproteins and proteoglycans: Hulmes, 1992), we could speculate that sponges lack some of these interfibrillar connections, which could have appeared later in animal evolution. This hypothesis is supported by the recent work of (Yamada et al., 2011). Although 
more information is certainly needed, this structural characteristic could be at the base of the macro and micro diversity in the phenomena occurring in the two phyla. A second point is the relevant physiological difference in terms of the timescale of the mechanical changes. In echinoderms this is usually much shorter, particularly if the destiffening process is considered: the most drastic destiffening phenomenon in echinoderms is represented by autotomy, which can occur in a fraction of a second (Wilkie, 2005) and is a much more rapid than propagule release in sponges, which lasts at least several days. This leads us to the third point. The differences in timescale of the two processes are probably due to the presence or absence of a form of neural control: direct control exerted by a well developed nervous system is clearly demonstrated in echinoderms, whereas this component is obviously lacking in sponges where only a possible (neuro-)endocrine regulation could be involved. It is intriguing that mechanical changes occurring in mammalian connective tissues (uterine cervix relaxation at parturition) can take hours to days and, indeed, are regulated by endocrine mechanisms rather than nervous stimuli. These functional analogies between sponge and mammalian connective tissue open new perspectives and need to be explored appropriately in terms of their evolutionary implications. In particular, the possible sensitivity of sponge mutability to neuro-active agents, provokes speculation on the evolutionary pathway leading to the development of mutability phenomena in the animal kingdom.

In both animal models mutability is apparently based on a cellmediated mechanism (Wilkie, 2005; Wilkie et al., 2006). In echinoderms the putative effector cells are the JLCs. In sponges, functionally analogous cells have not been definitively identified yet, although the most promising candidates are the gray cells, which share some features with echinoderm JLCs. Independently of the effector cells, in both echinoderms and sponges the main mechanism governing mutability appears to be a variation in collagen interfibrillar cohesive forces and reciprocal sliding.

It is topical that in both echinoderms and sponges mutability is strongly affected by exogenous environmental factors (such as temperature, $\mathrm{pH}$ and ionic composition), although not always in the same way. For example decreasing temperature reduces mechanical resistance in starfish (Hidaka, 1983) but has the opposite effect in sponges (Fassini et al., 2012). On the other hand, $\left[\mathrm{Ca}^{2+}\right]$ variations exert similar effects on both animal models.

Overall, this review underlines once more the striking mechanical performance of echinoderm and sponge connective tissues, which are highly important for the physiology and ecology of these animals, being employed as an effective defence mechanism (e.g. a rapid increase in the stiffness of the body in holothurians and sponges may make them more resistant to predation) or involved in successful asexual reproduction phenomena. These aspects, coupled with the responsiveness of sponge and echinoderm dynamic tissues to exogenous factors, make these animals potentially vulnerable to global environmental changes including warming, acidification and chemical contamination of the marine environment.

\section{Acknowledgements}

The present work received financial support from the CARIPLO Foundation (MIMESIS Project). We are grateful to the Area Marina Protetta of Isola di Bergeggi (SV, Italy) and Area Marina Protetta of Portofino for permission to collect experimental animals. We thank Dr. F. Lembo for technical support.

\section{Appendix A}

Some technical aspects related to the original data and results described in this review article are provided below.

\section{Immunofluorescence}

The lower half of the experimental sea urchins, which includes the masticatory apparatus, peristomial membrane and CDLs, was fixed with $4 \%$ paraformaldehyde in phosphate buffered saline (PBS) for 15 $\mathrm{min} / 1 \mathrm{~h}$ at room temperature. CDLs were excised, washed with PBS, dehydrated with an ethanol series (25\%,50\% in PBS, 70\% in distilled water) and maintained at $4{ }^{\circ} \mathrm{C}$ until used. Rehydrated samples $(50 \%$ ethanol $/ 50 \%$ PBS, 25\% ethanol/75\% PBS, 100\% PBS) were permeabilized with PBTT (0.1\% Tween-20, $0.1 \%$ Triton X-100 in PBS) for 20 min, washed three times in PBS and incubated in 10\% goat serum (GS) in PBTT (0.05\% Tween-20, 0.05\% Triton X-100 in PBS) for $1 \mathrm{~h}$. Then, the samples were treated overnight at $4{ }^{\circ} \mathrm{C}$ with the following primary antibodies diluted 1:50 in PBTT: mouse monoclonal (5B5 1h fixation) to fibroblast (Abcam, ab44971) and mouse monoclonal (1E11 - 15 min fixation) to echinoderm nervous system (kindly provided by Dr. Robert Burke; see Burke et al., 2006). After washes in PBS, samples were incubated in 1\% BSA in PBS for $1 \mathrm{~h}$ at room temperature, washed in PBS and then incubated at $4{ }^{\circ} \mathrm{C}$ overnight in PBS/ TRITC conjugated goat anti-mouse $(1: 200)$. Next, the samples were washed in PBS, mounted in 80\% glycerol in PBS on microscope slides and examined using a Leica TCSNT confocal laser scanning microscope (Leica Microsystems, Heidelberg, Germany), equipped with a laser argon/krypton, $75 \mathrm{mV}$ multiline. As negative controls, samples were processed without primary antibody incubation.

\section{Sponge viscosity calculation in standard condition.}

Beam-shaped samples $2.5 \times 2.5 \times 15 \mathrm{~mm}$ in size were cut from both the ectosome (discarding the exopinacoderm) and choanosome regions. Both extremities of each sample were attached to rigid plastic strips using cyanoacrylate cement leaving $10 \mathrm{~mm}$ in the middle between the frames. Samples were placed in petri dishes filled with ASW for $4 \mathrm{~h}$ before testing. The lower part of the samples of both ectosome and choanosome were then attached to a fixed hook while the upper part was clamped to the lever of an isotonic force transducer (Harvard apparatus) connected to an AD Instruments recording device. On the other side of the lever different loads were attached. Elongation of the samples was digitally recorded with LabChart software. During the experiment samples were immersed in ASW. The viscosity was calculated by dividing the rate of elongation in the constant phase by the applied stress. From five sponges three samples of ectosome and three samples of choanosome were prepared from each individual. To avoid sampling effects different loads $(1,5,10 \mathrm{~g})$ were applied in varying order during the experiments.

\section{Effect of seawater temperature and "wave action" on the creeping behaviour and re-shortening.}

Samples were prepared as described by Fassini et al. (2012). Briefly: beam-shaped samples of choanosome, $2 \times 2 \times 1.5 \mathrm{~mm}$ in size, were attached at one end to a plastic frame. At the other end a lead pellet $(0.56 \mathrm{~g})$ was attached with cyanoacrylate cement. Samples were later placed vertically in ASW and left undisturbed for $6 \mathrm{~h}$ in order to trigger the creeping phenomena. After $6 \mathrm{~h}$ the first group were placed at $15^{\circ}, 25^{\circ}$ and $25^{\circ}$ on an orbital shaker (100 rvm/min) for $18 \mathrm{~h}$. The mean elongation reached, calculated by means of images, was used to compare the speed of the creeping phenomenon.

\section{Effect of temperature on the destiffening process}

Beam-shaped samples, approximately $2 \times 2 \times 10 \mathrm{~mm}$ in size, were cut from the ectosome (discarding the exopinacoderm) and 
the choanosome region and placed in a petri dishes filled with ASW. Images were obtained using a camera mounted on a stereomicroscope soon after the excision and after $4 \mathrm{~h}$ of destiffening. The images were used to calculate with digital software the changes in thickness of the samples at specific points. One group of ectosome and choanosome samples was placed at $16{ }^{\circ} \mathrm{C}$ soon after the images acquisition at T0 while the other group was kept at RT $\left(26^{\circ} \mathrm{C}\right)$.

\section{References}

Aouacheria, A., Cluzel, C., Lethias, C., Gouy, M., Garrone, R., Exposito, J.Y., 2004. Invertebrate data predict an early emergence of vertebrate fibrillar collagen clades and an anti-incest model. Journal of Biological Chemistry 279, 47711-47719.

Bachmann, S., Pohla, H., Goldschmid, A., 1980. Phagocytes in the axial complex of the sea urchin, Sphaerechinus granularis (Lam.). Cell and Tissue Research 213 (1), $109-120$.

Barbaglio, A., Tricarico, S., Ribeiro, A., Ribeiro, C., Sugni, M., Di Benedetto, C., Wilkie, I., Barbosa, M., Bonasoro, F., Candia Carnevali, M.D., 2012. The mechanically adaptive connective tissue of echinoderms: its potential for bioinnovation in applied technology and ecology. Marine Environmental Research 76, 108-113.

Bavestrello, G., Benatti, U., Calcinai, B., Cattaneo-Vietti, R., Cerrano, C., Favre, A. Giovine, M., Lanza, S., Pronzato, R., Sara, M., 1998. Body polarity and mineral selectivity in the demosponge Chondrosia reniformis. Biological Bulletin - US 195, 120-125.

Birenheide, R., Tamori, M., Motokawa, T., Ohtani, M., Iwakoshi, E., Muneoka, Y., Fujita, T., Minakata, H., Nomoto, K., 1998. Peptides controlling stiffness of connective tissue in sea cucumbers. Biological Bulletin - US 194, 253-259.

Bonasoro, F., Wilkie, I.C., Bavestrello, G., Cerrano, C., Carnevali, M.D.C., 2001. Dynamic structure of the mesohyl in the sponge Chondrosia reniformis (Porifera, Demospongiae). Zoomorphology 121, 109-121.

Boury-Esnault, N., Muricy, G., Gallissian, M.-F., Vacelet, J., 1995. Sponges without skeleton: a new Mediterranean genus of Homoscleromorpha (Porifera, Demospongiae). Ophelia 43, 25-43.

Burke, R.D., Bouland, C., Sanderson, A.I., 1989. Collagen diversity in the sea-urchin Strongylocentrotus-Purpuratus. Comparative Biochemistry and Physiology B 94 $41-44$

Burke, R.D., Osborne, L., Wang, D., Murabe, N., Yaguchi, S., Nakajima, Y., 2006. Neuron-specific expression of a synaptotagmin gene in the sea urchin Strongylocentrotus purpuratus. Journal of Comparative Neurobiology 496, 244-251.

Byrne, M., 1985. The mechanical properties of the autotomy tissues of the holothurian Eupentacta quinquesemita and the effects of certain physicochemical agents. Journal of Experimental Biology 117, 69-86.

Byrne, M., 1986. The ultrastructure of the morula cells of Eupentacta quinquesemita (Echinodermata: Holothuroidea) and their role in the maintenance of the extracellular matrix. Journal of Morphology 188, 179-189.

Chapman, E.R., 2002. Synaptotagmin: a Ca ${ }^{(2+)}$ sensor that triggers exocytosis? Nature reviews. Molecular Cell Biology 3, 498-508.

Cluzel, C., Lethias, C., Garrone, R., Exposito, J.Y., 2000. Sea urchin fibrillar collagen 2alpha chain participates in heterotrimeric molecules of (1alpha)(2)2alpha stoichiometry. Matrix Biology 19, 545-547.

Cluzel, C., Lethias, C., Garrone, R., Exposito, J.Y., 2004. Distinct maturations of Npropeptide domains in fibrillar procollagen molecules involved in the formation of heterotypic fibrils in adult sea urchin collagenous tissues. Journal of Biological Chemistry 279, 9811-9817.

Connes, R., 1967. Structure et développement des bourgeons chez l'éponge siliceuse Tethia lyncurium Lamarck. Recherches expérimentales et cytologiques. Archives de zoologie expérimentale et générale 108, 39.

D’Alessio, M., Ramirez, F., Suzuki, H.R., Solursh, M., Gambino, R., 1990. Cloning of fibrillar collagen gene expressed in the mesenchymal cells of the developing sea urchin embryo. Journal of Biological Chemistry 265, 7050-7054.

Di Camillo, C.G., Coppari, M., Bartolucci, I., Bo, M., Betti, F., Bertolino, M., Calcinai, B. Cerrano, C., De Grandis, G., Bavestrello, G., 2012. Temporal variations in growth and reproduction of Tedania anhelans and Chondrosia reniformis in the North Adriatic Sea. Hydrobiologia 687, 299-313.

Doljanski, F., 2004. The sculpturing role of fibroblast-like cells in morphogenesis. Perspectives in Biology and Medicine 47, 339-356.

Exposito, J.Y., Boute, N., Deleage, G., Garrone, R., 1995. Characterization of two genes coding for a similar four-cysteine motif of the amino-terminal propeptide of a sea urchin fibrillar collagen. European Journal of Biochemistry/FEBS 234, 59-65.

Exposito, J.Y., Dalessio, M., Ramirez, F., 1992. Novel amino-terminal propeptide configuration in a fibrillar procollagen undergoing alternative splicing. Journal of Biological Chemistry 267, 17404-17408.

Exposito, J.Y., Valcourt, U., Cluzel, C., Lethias, C., 2010. The fibrillar collagen family International Journal of Molecular Sciences 11, 407-426.

Fassini, D., Parma, L., Wilkie, I.C., Bavestrello, G., Bonasoro, F., Carnevali, M.D.C., 2012. Ecophysiology of mesohyl creep in the demosponge Chondrosia reniformis (Porifera: Chondrosida). Journal of Experimental Marine Biology and Ecology 428, 24-31.

Gaino, E., Pansini, M., Pronzato, R., Cicogna, F., 1991. Morphological and structural variations in Clathrina clathrus (Porifera, Calcispongiae). In: Reitner, J., Keupp, H. (Eds.), Fossil and Recent Sponges. Springer, Berlin Heidelberg, pp. 360-371.
Gaino, E., Pronzato, R., 1983. Etude en microscopie électronique du filament des formes étirées chez Chondrilla nucula Schmidt (Porifera Demospongiae). Annales des sciences naturelles. Zoologie et biologie animale 5, 14 .

Heinemann, S., Ehrlich, H., Douglas, T., Heinemann, C., Worch, H., Schatton, W., Hanke, T., 2007. Ultrastructural studies on the collagen of the marine sponge Chondrosia reniformis Nardo. Biomacromolecules 8, 3452-3457.

Hennebert, E., Haesaerts, D., Dubois, P., Flammang, P., 2010. Evaluation of the different forces brought into play during tube foot activities in sea stars. Journal of Experimental Biology 213, 1162-1174.

Hidaka, M., 1983. Effects of certain physico-chemical agents on the mechanical properties of the catch apparatus of the sea urchin spine. Journal of Experimental Biology 103, 15.

Hidaka, M., Takahashi, K., 1983. Fine structure and mechanical properties of the catch apparatus of the sea-urchin spine, a collagenous connective tissue with muscle-like holding capacity. Journal of Experimental Biology 103, 1-14.

Hulmes, D.J., 1992. The collagen superfamily-diverse structures and assemblies. Essays in Biochemistry 27, 49-67.

Liu, Z.Y., Oliveira, A.C.M., Su, Y.C., 2010. Purification and characterization of pepsinsolubilized collagen from skin and connective tissue of giant red sea cucumber (Parastichopus californicus). Journal of Agricultural and Food Chemistry 58, 1270-1274.

Makarow, M., Ceulemans, R., Horn, L., 2009. Impacts of Ocean Acidification. European Science Foundation. Science policy briefing - August 2009.

Matsumura, T., 1974. Collagen fibrils of the sea cucumber, Stichopus japonicus: purification and morphological study. Connective Tissue Research 2, 117-125.

Matsumura, T., Hasegawa, M., Shigei, M., 1979. Collagen biochemistry and phylogeny of echinoderms. Comparative Biochemistry and Physiology Part B: Comparative Biochemistry 62, 101-105.

Mori, N., Doi, Y., Hara, K., Yoshizuka, M., Ohsato, K., Fujimoto, S., 1992. Role of multipotent fibroblasts in the healing colonic mucosa of rabbits. Ultrastructural and immunocytochemical study. Histology and Histopathology 7, 583-590.

Muricy, G., Boury-Esnault, N., Bézac, C., Vacelet, J., 1998. Taxonomic revision of the Mediterranean Plakina Schulze (Porifera, Demospongiae, Homoscleromorpha). Zoological Journal of the Linnean Society 124, 169-203.

Myllyharju, J., 2003. Prolyl 4-hydroxylases, the key enzymes of collagen biosynthesis. Matrix Biology 22, 15-24.

Nagai, T., Suzuki, N., 2000. Partial characterization of collagen from purple sea urchin (Anthocidaris crassispina) test. International Journal of Food Science \& Technology 35, 497-501.

Nemethy, G., 1988. Citation classic - the structure of water and hydrophobic bonding in proteins .3. The thermodynamic properties of hydrophobic bonds in proteins. Engineering, Technology \& Applied Science Research, 16-16.

Parma, L., Fassini, D., Bavestrello, G., Wilkie, I.C., Bonasoro, F., Carnevali, M.D.C., 2007. Ecology and physiology of mesohyl creep in Chondrosia reniformis. In: Custódio, M.R., Lôbo-Hajdu, G., Hajdu, E., Muricy, G. (Eds.), Porifera Research: Biodiversity, Innovation and Sustainability. Museu Nacional, Rio de Janeiro, pp. 503-508.

Pavans de Ceccatty, M., Thiney, Y., Garrone, R., 1970. Les bases ultrastructurales des communications intercellulaires dans les oscules de quelques éponges. In: Fry, W.G. (Ed.), The Biology of the Porifera. Symposia of the Zoological Society of London Academic Press, New York, pp. 449-466.

Pincebourde, S., Sanford, E., Helmuth, B., 2013. Survival and arm abscission are linked to regional heterothermy in an intertidal sea star. Journal of Experimental Biology 216, 2183-2191.

Pozzolini, M., Bruzzone, F., Berilli, V., Mussino, F., Cerrano, C., Benatti, U., Giovine, M., 2012. Molecular characterization of a nonfibrillar collagen from the marine sponge Chondrosia reniformis Nardo 1847 and positive effects of soluble silicates on its expression. Marine Biotechnology 14, 281-293.

Rhee, S., Grinnell, F., 2007. Fibroblast mechanics in 3D collagen matrices. Advanced Drug Delivery Reviews 59, 1299-1305.

Ribeiro, A.R., Barbaglio, A., Benedetto, C.D., Ribeiro, C.C., Wilkie, I.C., Carnevali, M.D.C., Barbosa, M.A., 2011. New insights into mutable collagenous tissue: correlations between the microstructure and mechanical state of a seaurchin ligament. PLoS ONE 6, e24822.

Ribeiro, A.R., Barbaglio, A., Oliveira, M.J., Ribeiro, C.C., Wilkie, I.C., Candia Carnevali, M.D., Barbosa, M.A., 2012a. Matrix metalloproteinases in a sea urchin ligament with adaptable mechanical properties. PLoS ONE 7, e49016.

Ribeiro, A.R., Barbaglio, A., Oliveira, M.J., Santos, R., Coelho, A.V., Ribeiro, C.C., Wilkie, I.C., Carnevali, M.D.C., Barbosa, M.A., 2012b. Correlations between the biochemistry and mechanical states of a sea-urchin ligament: a mutable collagenous structure. Biointerphases 7.

Robinson, J.J., 1997. Comparative biochemical analysis of sea urchin peristome and rat tail tendon collagen. Comparative Biochemistry and Physiology B 117, 307-313.

Saitta, B., Buttice, G., Gambino, R., 1989. Isolation of a putative collagen-like gene from the sea urchin Paracentrotus lividus. Biochemical and Biophysical Research Communications 158, 633-639.

Sarà, M., Vacelet, J., 1973. Écologie des Démosponges. In: Grassé, P.P. (Ed.), Traité de zoologie, Anatomie, systématique, biologie: Spongiaires. Masson, Paris, pp. 462-576.

Sidri, M., Milanese, M., Bummer, F., 2005. First observations on egg release in the oviparous sponge Chondrilla nucula (Demospongiae, Chondrosida, Chondrillidae) in the Mediterranean Sea. Invertebrate Biology 124, 91-97.

Smiley, S., Cloney, R.A., 1985. Ovulation and the fine-structure of the Stichopus californicus (Echinodermata, Holothuroidea) fecund ovarian tubules. Biological Bulletin-US 169, 342-364. 
Szulgit, G.K., Shadwick, R.E., 1994. The effects of calcium chelation and cell perforation on the mechanical properties of sea urchin ligaments. In: David, B., Guille, A., Féral, J.P., Roux, M. (Eds.), Echinoderms Through Time. Balkema, Rotterdam, pp. 887-892.

Tamariz, E., Grinnell, F., 2002. Modulation of fibroblast morphology and adhesion during collagen matrix remodeling. Molecular Biology of the Cell 13, 39153929.

Tamori, M., Takemae, C., Motokawa, T., 2010. Evidence that water exudes when holothurian connective tissue stiffens. Journal of Experimental Biology 213, 1960-1966.

Tamori, M., Yamada, A., Nishida, N., Motobayashi, Y., Oiwa, K., Motokawa, T., 2006. Tensilin-like stiffening protein from Holothuria leucospilota does not induce the stiffest state of catch connective tissue. Journal of Experimental Biology 209, 1594-1602.

Tricarico, S., Barbaglio, A., Burlini, N., Giacco, L.P.C.D., Ghilardi, A., Sugni, M., Benedetto, C.D., Bonasoro, F., Wilkie, I.C., Candia, M.D., 2012. New insight into mutable collagenous tissue: work in progress and applied perspectives. In: Proceedings Volume of the 7th European Echinoderm Conference. Zoosymposia, vol. 7. Springer, Heidelberg, pp. 279-285.

Trotter, J., Koob, T., 1995. Evidence that calcium-dependent cellular processes are involved in the stiffening response of holothurian dermis and that dermal cells contain an organic stiffening factor. Journal of Experimental Biology 198, 1951-1961.

Trotter, J.A., Koob, T.J. 1989. Collagen and proteoglycan in a sea urchin ligament with mutable mechanical properties. Cell and Tissue Research 258, 527-539.

Trotter, J.A., Koob, T.J., 1994. Biochemical characterization of fibrillar collagen from the mutable spine ligament of the sea-urchin Eucidaris Tribuloides. Comparative Biochemistry and Physiology B 107, 125-134.

Trotter, J.A., LyonsLevy, G., Thurmond, F.A., Koob, T.J., 1995. Covalent composition of collagen fibrils from the dermis of the sea cucumber, Cucumaria frondosa, a tissue with mutable mechanical properties. Comparative Biochemistry and Physiology A 112, 463-478.

Wessel, G.M., Marchase, R.B., McClay, D.R., 1984. Ontogeny of the basal lamina in the sea urchin embryo. Developmental Biology 103, 235-245.

Wilkie, I.C., 1983. Nervously mediated change in the mechanical properties of the cirral ligaments of a crinoid. Marine Behaviour and Physiology 9, 229-248.
Wilkie, I.C., 1988. Design for disaster: the ophiuroid intervertebral ligament as a typical mutable collagenous structure. In: Burke, R.D., Mladenov, P.V., Lambert, P., Parsley, R.L. (Eds.), Echinoderm Biology. Balkema, Rotterdam, pp. $25-38$.

Wilkie, I., 1996. Mechanical properties of the peristomial membrane of the cidaroid sea-urchin Stylocidaris affinis. Journal of Zoology, London 238, 557-569.

Wilkie, I.C., 2005. Mutable collagenous tissue: overview and biotechnologica perspective. Progress in Molecular and Subcellular Biology 39, 221-250.

Wilkie, I.C., Barbaglio, A., Maclaren, W.M., Carnevali, M.D.C., 2010. Physiological and immunocytochemical evidence that glutamatergic neurotransmission is involved in the activation of arm autotomy in the featherstar Antedon mediterranea (Echinodermata: Crinoidea). Journal of Experimental Biology 213, $2104-2115$

Wilkie, I.C., Carnevali, M.D.C., Andrietti, F., 1994. Microarchitecture and mechanics of the sea-urchin peristomial membrane. Zoological Bulletin 61, 39-51.

Wilkie, I.C., Carnevali, M.D.C., Bonasoro, F. 1992. The compass depressors of Paracentrotus lividus (Echinodermata, Echinoida) - ultrastructural and mechanical aspects of their variable tensility and contractility. Zoomorphology 112, 143153.

Wilkie, I.C., Emson, R.H., 1987. The tendons of Ophiocomina nigra and their role in autotomy. Zoomorphology 107, 33-44.

Wilkie, I.C., Parma, L., Bonasoro, F., Bavestrello, G., Cerrano, C., Carnevali, M.D.C. 2006. Mechanical adaptability of a sponge extracellular matrix: evidence for cellular control of mesohyl stiffness in Chondrosia reniformis Nardo. Journal of Experimental Biology 209, 4436-4443.

Yamada, A., Tamori, M., Iketani, T., Oiwa, K., Motokawa, T., 2010. A novel stiffening factor inducing the stiffest state of holothurian catch connective tissue. Journal of Experimental Biology 213, 3416-3422.

Yamada, S., Sugahara, K., Özbek, S., 2011. Evolution of glycosaminoglycans: comparative biochemical study. Communicative \& Integrative Biology 4, 150158.

Zilberberg, C., Sole-Cava, A.M., Klautau, M., 2006. The extent of asexual reproduction in sponges of the genus Chondrilla (Demospongiae: Chondrosida) from the Caribbean and the Brazilian coasts. Journal of Experimental Marine Biology and Ecology 336, 211-220. 